\title{
Function of Silver in the Mixed ITE Activators for Lead-acid Batteries
}

\author{
Michio Sugawara ${ }^{1}$, Atsushi Suzuki ${ }^{2}$, Kazuhiro Tachibana ${ }^{3}$, Tatsuo Nishina ${ }^{4}$, and Akiya Kozawa ${ }^{5}$ \\ ${ }^{I}$ Department of Chemistry \& Chemical Engineering, Yamagata University, sugawara@yz.yamagata-u.ac.jp \\ ${ }^{2}$ Department of Chemistry \& Chemical Engineering, Yamagata University \\ ${ }^{3}$ Department of Chemistry \& Chemical Engineering, Yamagata University, c1_lab.@egroups.co.jp \\ ${ }^{4}$ Graduate school of Science \& Engineering, Yamagata University,nishina@yz.yamagata-u.ac.jp \\ ${ }^{5}$ ITE Battery Research Institute, akiya-kozawa@mwb.biglobe.ne.jp
}

\begin{abstract}
The behaviors of $\mathrm{Ag}^{+}$and activator were studied on $\mathrm{Pb}$ anode for lead-acid batteries. The deposition of Ag and dissolution of $\mathrm{Ag}^{+}$take place at lower potential than redox couple of $\mathrm{Pb} / \mathrm{PbSO}_{4}$. This process may be considered to activate the reaction in the redox couple of $\mathrm{Pb} / \mathrm{PbSO}_{4}$. The activator molecules are less adsorbable on bear $\mathrm{Pb}$, and adsorbed easily on $\mathrm{PbSO}_{4}$ formed on $\mathrm{Pb}$. The complex ions of $\mathrm{Ag}^{+}$and activator molecule are adsorbable on bear $\mathrm{Pb}$, and $\mathrm{PbSO}_{4}$ is initially formed on the adsorbed layer of complex ions.
\end{abstract}

\section{Keywords}

lead-acid battery, anode, electrolyte, silver ion, organic polymer, activator

\section{INTRODUCTION}

The ITE mixed polymer activator added to electrolyte of lead-acid batteries have been found to extend battery life. The anode (negative electrode) sulfation is the main cause of deterioration in performance of the lead-acid batteries. It has been explained that the activator molecules are adsorbed on anode to produce the beneficial action for battery life.

On the other hand, the active materials are impregnated on grid alloy such as $\mathrm{Pb}-\mathrm{Ca}, \mathrm{Pb}-\mathrm{Sb}$ and so on, and the alloy components may be dissolved as metal ions in the electrolyte during charge and discharge cycles. The additional alloy components are added for giving corrosion resistance property.

It is important to study the behaviors of dissolved metal ions from the grid alloy for battery performance. The silver is being used as an alloy component of $\mathrm{Pb}-\mathrm{Ca}$ grid. This fact is worth paying particular attention, because the participation of $\mathrm{Ag}^{+}$in the anode reaction of $\mathrm{Pb}$ seems to be important for battery performance in the electrolyte containing activator lmolecules. This paper describes the effects of $\mathrm{Ag}^{+}$and activator on anode reaction on $\mathrm{Pb}$ by cyclic voltammmetry.

\section{EXPERIMENTAL}

Cyclic voltammograms (CV) were recorded as follows. The test electrode was lead plate $\left(99.99 \%, 1 \times 1 \mathrm{~cm}^{2}\right)$, which was chemically polished in $\mathrm{CH}_{3} \mathrm{COOH}-\mathrm{H}_{2} \mathrm{O}_{2}$ solution at room temperature just before measurements of CV. Counter electrode was cylindrical lead with large surface area. Reference electrode was $\mathrm{Hg} / \mathrm{Hg}_{2} \mathrm{SO}_{4} / 5 \mathrm{M}$ $\mathrm{H}_{2} \mathrm{SO}_{4}$.

Electrolyte was $5 \mathrm{M} \mathrm{H}_{2} \mathrm{SO}_{4}$ with/without additives, which were $\mathrm{Ag}_{2} \mathrm{SO}_{4}$ as $\mathrm{Ag}^{+}$and the ITE mixed activator composed of polyvinylalcohol. The concentration of $\mathrm{Ag}_{2} \mathrm{SO}_{4}$ and activator was $2 \mathrm{mg} / 100 \mathrm{ml}_{5} \mathrm{M} \mathrm{H}_{2} \mathrm{SO}_{4}$, and $1.0 \mathrm{wt} . \%$, respectively. The test electrode was immersed in the electrolyte, and scanned negatively from the spontaneous potential $(-1.05 \mathrm{~V})$ to hydrogen evolution region. Then, the potential was positively scanned to $-0.6 \mathrm{~V}$, and the scan was repeated between this potential region at the scan rate of $10 \mathrm{mV} / \mathrm{s}$.

\section{RESULTS}

Figure 1 shows the $\mathrm{CV}$ curves of $\mathrm{Pb}$ electrode in $5 \mathrm{M}$ $\mathrm{H}_{2} \mathrm{SO}_{4}$ and $5 \mathrm{M} \mathrm{H}_{2} \mathrm{SO}_{4}-\mathrm{Ag}^{+}$solutions. The redox couple

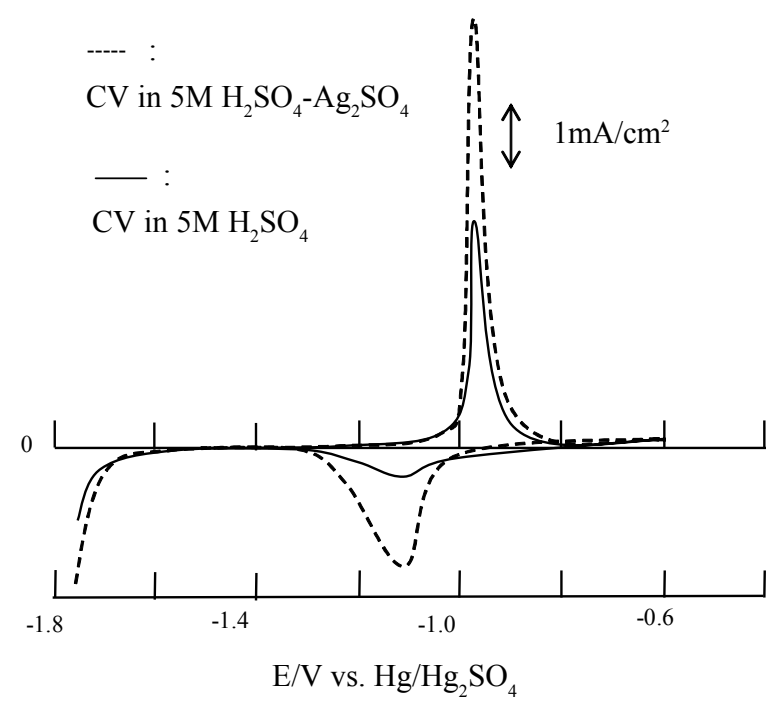

Fig. 1 Cyclic voltammograms of $\mathrm{Pb}$ in $5 \mathrm{M} \mathrm{H}_{2} \mathrm{SO}_{4}$ and $5 \mathrm{M} \mathrm{H}_{2} \mathrm{SO}_{4}-\mathrm{Ag}^{+}$ 
of $\mathrm{Pb} / \mathrm{PbSO}_{4}$ appears around $-1.1 \mathrm{~V}$, and corresponds to the charge and discharge reaction on anode of lead-acid battery. The hydrogen evolution current was observed below $-1.6 \mathrm{~V}$. When $\mathrm{Ag}^{+}$was added to the electrolyte, the reaction of redox couple at $-1.1 \mathrm{~V}$ was activated to increased the current two times. On the other hand, the hydrogen evolution deviates to positive potential. The $\mathrm{Ag}$ is formed on $\mathrm{Pb}$ at lower potential and decreases hydrogen overpotential.

Figure 2 shows the $\mathrm{CV}$ in $5 \mathrm{M} \mathrm{H}_{2} \mathrm{SO}_{4}$-activator solution with that in $5 \mathrm{M} \mathrm{H}_{2} \mathrm{SO}_{4}$. The addition of activator decreases the current in the redox couple of $\mathrm{Pb} / \mathrm{PbSO}_{4}$, and splits the anodic current of redox couple into two peaks. This suggests that the two processes take part in the formation of $\mathrm{PbSO}_{4}$ from $\mathrm{Pb}$. There is no effect of activator on hydrogen evolution region.

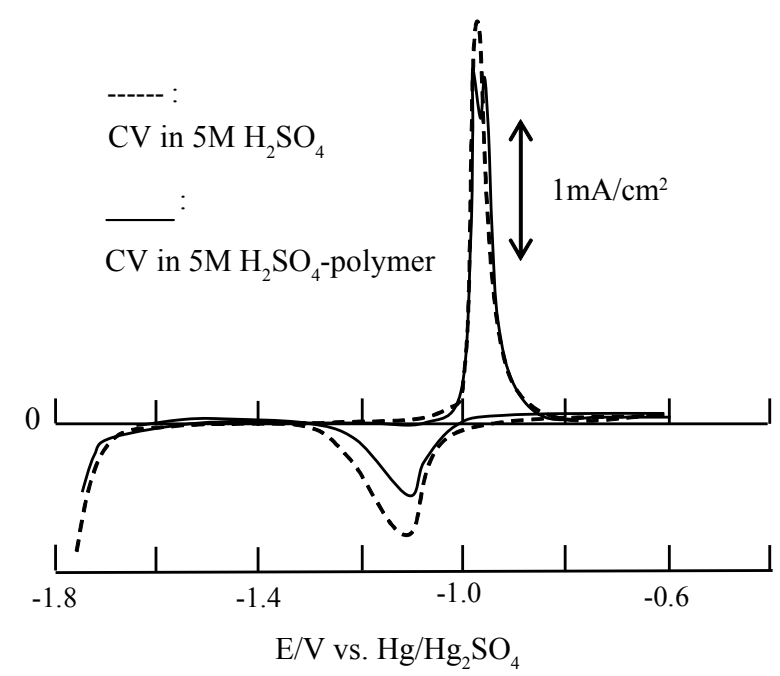

Fig. 2 Cyclic voltammograms of $\mathrm{Pb}$ in $5 \mathrm{M} \mathrm{H}_{2} \mathrm{SO}_{4}$ and $5 \mathrm{M} \mathrm{H}_{2} \mathrm{SO}_{4}$-activator

Figure 3 shows the $\mathrm{CV}$ in $5 \mathrm{M} \mathrm{H}_{2} \mathrm{SO}_{4}-\mathrm{Ag}^{+}$-activator solution compared with that in $5 \mathrm{M} \mathrm{H}_{2} \mathrm{SO}_{4}$-activator. The

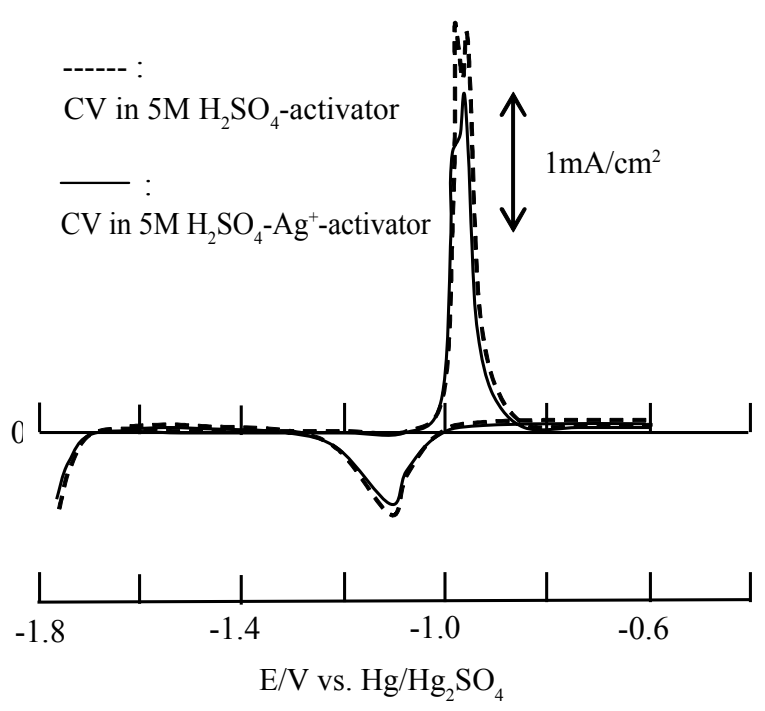

Fig. 3 Cyclic voltammograms of $\mathrm{Pb}$ in activator and activator and $\mathrm{Ag}^{+}$solution. first peak current observed in addition of only activator is decreased to give the shoulder in CV. It is considered that some species may be adsorbed on $\mathrm{Pb}$. The hydrogen evolution potential deviates slightly to negative region, because of the presence of $\mathrm{Ag}^{+}$.

\section{4, DISCUSSION}

Figure 4 shows the mechanisms, in which the addition of $\mathrm{Ag}_{2} \mathrm{SO}_{4}$ as $\mathrm{Ag}^{+}$increases the current in the redox couple of $\mathrm{Pb} / \mathrm{PbSO} 4$. When $\mathrm{Pb}$ electrode is polarized negatively near hydrogen evolution potential, $\mathrm{Ag}+$ is reduced to deposit $\mathrm{Ag}$ metal on $\mathrm{Pb}$. When this electrode is scanned to positive direction, the deposited $\mathrm{Ag}$ dissolves as $\mathrm{Ag}^{+}$even before $\mathrm{PbSO}_{4}$ formation potential. Such deposition and dissolution during potential scan gives fresh and bear surface of $\mathrm{Pb}$ to activate $\mathrm{PbSO}_{4}$ formation. Accordingly, the redox current $\mathrm{Pb} / \mathrm{PbSO}_{4}$ is significantly increased in $\mathrm{Ag}^{+}$containing solution.

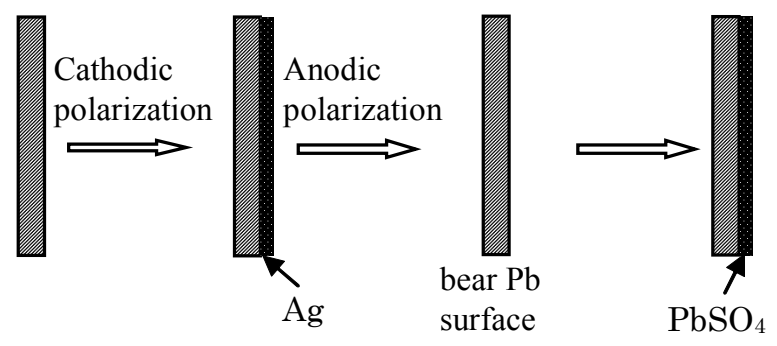

Fig. 4 Mechanisms of the formation of $\mathrm{PbSO}_{4}$ in the redox couple of $\mathrm{Pb} / \mathrm{PbSO}_{4}$

Figure 5 shows the illustration to explain the effect of activator on the oxidation of $\mathrm{Pb}$ to $\mathrm{PbSO}_{4}$. It is considered that the adsorption of activator takes an important role on this reaction. Activator has negative charge on oxygen atoms of the molecules, and hence is easily adsorbed on positive center of the electrode. If the $\mathrm{Pb}$ electrode is polarized near hydrogen evolution region, activator molecules are less adsorbable. Therefore, there is no deviation of hydrogen evolution potential compared with that in $5 \mathrm{M} \mathrm{H}_{2} \mathrm{SO}_{4}$.

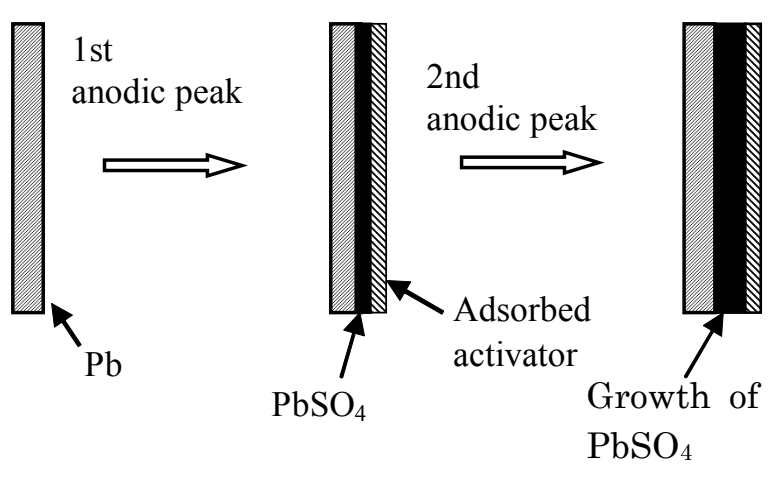

Fig. 5 Mechanism of the formation of $\mathrm{PbSO}_{4}$ in the activator containing solution 
In the positive scan of $\mathrm{Pb}$ electrode from hydrogen evolution region, the oxidation of $\mathrm{Pb}$ to $\mathrm{PbSO}_{4}$ starts on bear $\mathrm{Pb}$ surface. The electrode is covered with $\mathrm{PbSO}_{4}$ by anodic current. The electrode covered with $\mathrm{PbSO}_{4}$ is positively charged, and then the activator molecules are adsorbed on the film of $\mathrm{PbSO}_{4}$. It is considered that this process gives the first peak current. The growth of $\mathrm{PbSO}_{4}$ proceeds on the electrode with adsorbed activator to give the second peak current.

Figure 6 shows the reaction mechanism in the presence of both $\mathrm{Ag}^{+}$and activator molecules. In this case, the first peak current is decreased to give the shoulder in CV curve. This result indicates the some species are adsorbed on $\mathrm{Pb}$ electrode before the initial formation of $\mathrm{PbSO}_{4}$.

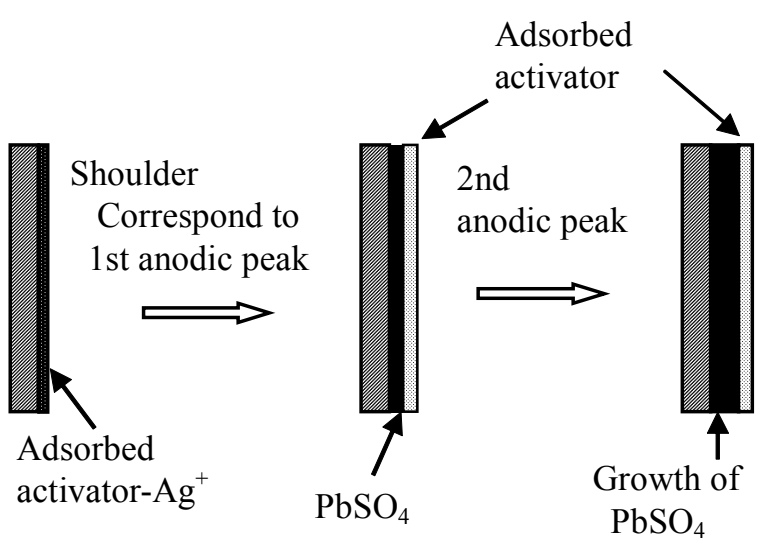

Fig. 6 Mechanism of the formation of $\mathrm{PbSO}_{4}$ in the activator and $\mathrm{Ag}^{+}$containing solution

The complex ions of $\mathrm{Ag}^{+}$and activator molecules must be considered for the explanation of CV curve. Activator itself is less adsorbable species on $\mathrm{Pb}$ polarized negatively. The activator molecules with negative charge center react with $\mathrm{Ag}^{+}$to give complex ions. This is more adsorbable on $\mathrm{Pb}$ than free activator molecules. Accordingly, the first peak current is decreased to give the shoulder by the $\mathrm{PbSO}_{4}$ formation on the polymer adsorbed layer. Then, the formation and growth of $\mathrm{PbSO}_{4}$ proceed on the electrode adsorbed by activator to give the second peak current in $\mathrm{CV}$.

\section{CONCLUSION}

The results obtained are summarized as follows.

(1) The addition of $\mathrm{Ag}^{+}$activates the reaction of $\mathrm{Pb}$ / $\mathrm{PbSO}_{4}$ redox couple, and deviates the hydrogen evolution to positive region.

(2) The activator affects the reaction in redox couple of $\mathrm{Pb} / \mathrm{PbSO}_{4}$. This is explained by adsorption of activator on $\mathrm{Pb}$ and $\mathrm{PbSO}_{4}$. The activator molecules are less adsorbable on $\mathrm{Pb}$ and adsorbed on $\mathrm{PbSO}_{4}$.

(3) When both of activator and $\mathrm{Ag}^{+}$are present, the complex ion of $\mathrm{Ag}^{+}$and activator molecules is adsorbed on $\mathrm{Pb}$. The initial formation of $\mathrm{PbSO}_{4}$ proceeds on $\mathrm{Pb}$ adsorbed by the complex ion.

\section{References}

Furukawa, J., Y. Nanyo and S. Shiga, Development of New Positive-grid Alloy and its Application to Longlife Battery for Automotive Industry, J. Power Sources, Vol. 133, No. 1, 25-31, 2004.

Kozawa, A., T. Okayasu, A. Matsuda, K. Sakai, M. Yamashita, S. Ikeda, T. Nishina, M. Sugawara, J. C. Nardi, and R. J. Brodd, New Technology to extend the Life 2 3 Times in Lead-acd Battery and Contribution to Worldwide Environment, Kagaku Kogyo, Vol. 60, 164-166, 2004.

Minami, S., A. Kozawa, L. Yang, Y. Suzuki, N. Iwata, S. Ikeda, H. Ikeda, M. Wada, T. Okayasu, M. Sugawara, J. C. Nardi, R. J. Brodd, and C. C. Chan, Eight Year's Summary of ITE's Organic Activator Tests for New and Used Lead-acid Batteries, Journal of Asian Electric Vehicles, Vol. 2, No. 2, 623-626, 2004.

Mori, Y., T. Tachibana, S. Ikeda, I. Katsuyama, A. Kozawa, and R. J. Brodd, Behavior of Dissolved Antimony in Lead-acid Batteries Electrolyte and New Proposed Treatments for Battery and Electrolyte Generation and Reuse, ITE Letters, Vol. 4, No.4, 432435, 2003.

Nishina, T., K. Tachibana, J. C. Nardi, C. F. O'Brien, S. Mase, A. Kozawa, and R. J. Brodd, Summary of the Experience of Thirty Companies in Testing the ITE Lead-acid Battery Activator, ITE Letters, Vol. 4, No. 4, 436-449, 2003.

Sugawara, M., K. Tachibana, A. Kozawa, M. Yamashita, S. Ikeda, and R. J. Brodd, Beneficial Action of Complex Organic Polymer Additions for the Regeneration of Deteriorated Battery, ITE Letters, Vol. 4, No. 4, 424-431, 2003.

Tachibana, K., N. Nishina, D. Aso, M. Sugawara, K. Ogata, J. C. Nardi, and R. J. Brodd, ITE's Proposed Standard Tests for Reactivation of Deteriorated Leadacid Batteries, ITE Letters, Vol. 4, No. 3, 308-317, 2003.

Torcheux, L., A. Villaron., and M. Bellmunt., Grid Technololgy and Silver Additive Influence on VRLAAGM Batteries Performance for Electric Vehicle, $J$. Power Sources, Vol. 85, No. 1, 157-163, 2000.

(Received December 5, 2005; accepted December 28, 2005) 